tributed by members of the staff of Imperial Chemical Industries, Ltd., an organization which has probably had greater experience in the use of work study than any other in Great Britain. The whole volume has been well put together and will be of practical value not only to those who are introducing work study techniques into factories and offices but also to those who wish to familiarize themselves with its methods and jargon. Copies of the proceedings can be obtained from the Association of British Chemical Manufacturers, Cecil Chambers, 86 Strand, London, W.C.2.

\section{Occupational Medicine in Finland}

THE Finnish Institute of Occupational Health has recently published its annual report for 1953, which shows how its work is rapidly expanding. In the past two years its staff has increased from 84 to 121 and now comprises the following departments: general, medical, physiological, psychological and industrial hygiene. In the physiological department particularly, a good deal of work has been carried out-some of it with the aid of money from Statecontrolled football pools-on such topics as the mineral composition of thermal sweat, age and athletic performance in ball games, ski-ing and in wood-cutting, factor analysis of hæmatological changes in heavy manual work and the effects of a ski-ing season on physical fitness. In the psychological section the following subjects have been investigated: job analysis in the metal industry, selection tests for miners, statistical analyses of accident proneness with especial regard to the relationship between age and accident proneness, fitness tests for drivers, method of selecting X-ray assistants for hospitals, studies of the condition of intoxication and so-called "hang-over studies". The report also contains a list of publications of the Institute during the year, which was marked by twenty generous donations amounting to a total of 1,350,000 Finnish marks. The donors came from industry, insurance companies and workers' organizations.

Pest Infestation Laboratory: Report for 1953

THE annual report for 1953 of the Pest Infestation Laboratory, Slough, of the Department of Scientific and Industrial Research (pp. iv $+46+4$ plates. London: H.M.S.O., 1954; $2 s$. net), shows that the range of activities of this centre of entomological research continues to enlarge. During the year the new biochemical laboratories were opened, and this will greatly facilitate the more fundamental work in which the metabolism of various insecticides is being studied, with the object of discovering their mode of action and the nature of the resistance which many insects are developing to certain types of insecticides. But the greater part of the work reported is of immediate practical importance. The ability of a wide range of pests and potential pests to survive under winter conditions in unheated buildings has been studied. In preliminary trials it has been found that sacks impregnated with a mixture of pyrethrins and piperoxyl butoxide retain their insecticidal properties from six to nine months. A simple electrical device, depending upon changes in conductivity, has been developed for rapid estimation of the watercontent of bagged grain. Although not so accurate as the usual methods, this procedure is extremely simple and rapid and should prove of much practical value. One of the most important changes in policy which is apparent in this report is a great increase in the amount of work which the Pest Infestation Laboratory is doing for the British Colonies. Most of these investigations concern storage problems, such as the underground storage of grain in pits, the susceptibility of rice to attack by mites, and the contamination of African maize by insect remains and much other filth since the adoption of hammer mills in place of the old method of winnowing the grain and grinding between stones or by pestle and mortar. It is a recommendation of the Pest Infesta,tion Research Board that the Colonial side of the Laboratory's work should be still further strengthened.

\section{Cytology of Puccinia coronata}

STUDres of chromosomes in germinating sporidia of Puccinia coronata f. secalis, by R. C. McGinnis (Canad. J. Bot., 32, 213; 1954), show that three are present in the haploid nucleus. Hitherto, the very minute size of the chromosomes in the rust fungi has tended to deter cytologists from tackling these organisms. In an earlier paper (ibid., 31, 522; 1953) the same author has reviewed the literature and also recorded a haploid chromosome number of six for P. graminis and presented evidence of polyploidy. For if this species is an auto- or allotetraploid, then species with a lower chromosome number must have contributed to its origin. The present study contributes part of the relevant evidence: one of the illustrations shows a nucleus at anaphase with six daughter chromosomes migrating to the poles. It is suggested that three is probably the basic number for the genus and that $P$. coronata may be a constituent species of $P$. graminis.

\section{Forestry in New Zealand}

The New Zealand Forest Service has started a new "Information Series" of pamphlets, the first number of which is entitled "Forestry in New Zealand" and is an extract from the "New Zealand Official Year-Book" (pp. 27. Wellington : Government Printer, 1953). The pamphlet is written for the public and deals with the present position of forestry in New Zealand under the headings of national forest policy, forest resources, forest authority, forest management, fire protection, soil conservation, public and private forestry, reclamation of sand dunes, finance of State activity, forest utilization, overseas tradc research, principal forest trees, and strength properties of New Zealand timbers. The annual reports of the Service deal with those aspects of forestry work in the routine fashion. But, as the director of forestry complained in his annual report for 1950-51, the public does not read these reportsa fact scarcely to be wondered at in any country where government routine reports are in question. The pamphlet here considered is the director's answer. A periodical brief review for the public of the forestry position in every country owning forests drawn up on these lines would prove of interest to many public men apart from the general reader. The opening statement on national forest policy displays both the object and method of the pamphlet. Forest policy is essentially one of conservation of all existing forests and expansion in bringing on to the ground additional forest areas where they are obviously required, whether of indigenous or exotic speeies, both on uplands and plains. Not only productivity, but also protective scenic and recreational facilities, should be considered in the objectives. In short, a national forest policy should be drawn for 